\title{
SITUATION AND EVALUATION OF BIOLOGICAL AND CHEMICAL CONTROL APPLICATIONS FOR FOREST IN TURKEY
}

\author{
AKYOL, A.*-SARIKAYA, O. \\ Departmant of Forest Engineering, Faculty of Forestry, Suleyman Demirel University \\ 32260 Isparta, Turkey \\ *Corresponding author \\ e-mail: ayhanakyol@sdu.edu.tr \\ phone: +90-246-211-3937; fax: +90-246-211-3948 \\ (Received 21 ${ }^{\text {st }}$ Apr 2017; accepted $4^{\text {th }}$ Jul 2017)
}

\begin{abstract}
Pest insect species cause important economic losses in Turkish forests by feeding on various parts of forest trees. To combat them, control methods such as chemical, biotechnical, mechanical and biological applications are used. Among them, biological control is the most important method for the ecological aspect. Technically, the first biological control practice in Turkish forests was launched in the last part of the 1960s. This study aimed to evaluate current control methods for Turkish forestry. For this purpose, biological and chemical control applications in Turkey have been examined and compared. Necessary data were obtained from the 28 Regional Directorates of Forestry in Turkey using a developed data collecting method. Collected data were classified as insect production numbers, control areas and expenditures according to years. Subsequently, the total and unit costs were calculated and the gain and loss amounts obtained were estimated. Based on the comparison between chemical and biological control methods, chemical control is approximately 1.4 times more expensive than biological control in Turkey. This indicates that chemical control is causing economic loss in addition to ecological damages. In conclusion, the primary benefit of biological control is that it restores ecological balance and thus ensures the continuity of ecosystem services. The secondary benefit is savings from lower costs. Therefore, the use of biological control to mitigate damage from insects in forest ecosystems is important for the ecological and economic sustainability of forest ecosystems. To this end, predatory species such as Rhizophagus grandis Gyll, Rhizophagus depressus (F.), Formica rufa L., Calosoma sycophanta (L.) and Thanasimus formicarius (L.) have been used for biological control operations in Turkish forestry in recent years.
\end{abstract}

Keywords: ecological-economic sustainability, pest control, natural balance, forest ecosystem

\section{Introduction}

The forest ecosystem is the most fundamental and indispensible element of human life on earth. The history of utilization of forest resources is as old as humanity. Ecosytem services like carbon sequestration, non wood forest products, biodiversity and other attemps to adress climate change have vital importance for humankind. For the sustainable management of an ecosystem, the factors that compose the ecosystem should also be in balance. From this perspective, insects that had a natural role in a forest ecosystem may proliferate excessively due to various reasons, including human impact. It is of great importance to restore the forest ecosystem back to its natural balance. In order to do so, it is necessary to identify the factors and take the required measures. It is imperative to protect and ensure the sustainability of this vital and indispensible element of life (Tolunay and Türkoğlu, 2014). Given that forest ecosystems constitute a whole with their specific soil structures, plant communities and other organisms, it is important to protect and develop forest ecosystems with a view to ensuring their long term sustainability (Akyol and Tolunay, 2014). 
Insects are among the most crucial threats to forests. In recent years, biological control methods that do not harm trees were proposed and put in practice to adress the disadvantages of chemical methods. The chemical insecticides that have negative effects and are dangerous for human health also lead to an insect resistance problem, which increases the pesticide cost because new compounds are needed. Today, it is understood that insecticides cannot provide a permanent solution for the control of insects. Biological control in which natural enemies of the pest insects are used avoids the negative consequences of chemical control on forest ecosystems.

Biological control can also be used to restore the natural balance from the human health perspective. The general principle of biological control is to protect, strengthen the natural enemy populations that have an impact on pest insects, and supplement them with imported species when needed. Technically, the first biological control practice in Turkish forests was launched in 1967 when Formica rufa was transplanted from the forest stands in North Anatolia to the Mediterranean region (Oğurlu, 2000). Predatory species such as Rhizophagus grandis Gyll, R. depressus (F.), Formica rufa L., Calosoma sycophanta (L.), Thanasimus formicarius (L.), as well as insectivore birds are used in biological control operations in Turkish forests; the rearing of predatory species was given priority after 2000s.

The ecological effects and consequences of insect control have been studied in the literature (Greatheat, 1976; Dijken, 1986; Brower, 1991; Van Lenteren, 2003; Orr, 2009; Uygun et al., 2010). However, there are only a limited number of studies that explore the economic aspects of insect control (Bokonon-Ganta, 2002; Born et al., 2005; Mc Fdyent, 2008; Fowler et al., 2016). In particular, there are very few studies in Turkey that explore the economic aspects of insect control methods. Existing studies mainly focus on the damage caused by insects to raw wood material and the associated economic loss. For example, Güngör and Daşdemir (2014) analysed the economic effects of Pityokteines curvidens Germ. on the sales of fir wood.

The native tree species in Turkish forests have lost many of their characteristics, especially in some regions, due to long years of irregular utilization and inappropriate interventions (Atmış et al., 2007). Besides raw wood materials, forests play an important role protecting biological diversity. Harmful insect species that lead to considerable economic losses in Turkish forests are controlled through various methods; the General Directorate of Forestry (GDF) spends a significant amount of money for that purpose. Therefore, this study evaluated the current status of biological control practices in Turkish forests and compared it with chemical controls method from the ecological-economical perspective.

\section{Materials and methods}

In this study, the insect control methods in Turkish forests were evaluated in general terms as a first step. Secondly, biological control methods and practices were examined. Finally, biological and chemical control methods were compared and analysed from an economical perspective. Data from 2004 to 2014 relating to these control methods, practices and economic expenditure in Turkey were evaluated. As it is difficult to express the benefits of sustainability of ecosystem services in insect control areas in economic and monetary terms, the costs of control methods were highlighted (Pak et al., 2010; Deniz and Ok, 2015). 
Data were collected separately from 28 Regional Directorates of Forestry across Turkey in 2015 and 2016. The collected data included information about the size and cost of areas where chemical methods were applied, successful and failed cases for chemical and biological control methods and amounts of predatory species provided. Total and unit costs were estimated, and the amount of profit and loss was determined. Previous costs were converted to 2015 values using the Domestic Producer Price Index (D-PPI). Moreover, the Turkish Central Bank's data were used for international audiences and the unit costs were converted to USD. In general economic evaluations, all costs were taken into account, irrespective of the success status of insect control efforts in the relevant areas. However, the areas where the methods were successful or failed were taken into account when comparing the biological and chemical control methods; not only the economy of a method but also its success at the intended level is important. Therefore, biological and chemical control methods were evaluated from the perspective of cost minimization and cost saving regardless of their ecological impacts.

\section{Results and discussion}

\section{Biological control practices in Turkish forests}

The insect control methods that have been implemented in Turkey include chemical control with insecticides, biotechnical control with pheromone and pheromone traps, and mechanical control by way of collecting nest and egg batches of pine processionary moths (Thaumetopoea wilkinsoni and T. pityocampa) or trap trees for bark beetles (GDF, 2015). However, biological control methods appear to be preferred over these other control methods in recent years (Fig. 1); chemical control methods that cause harm to forests, organisms and people are largely abandoned.

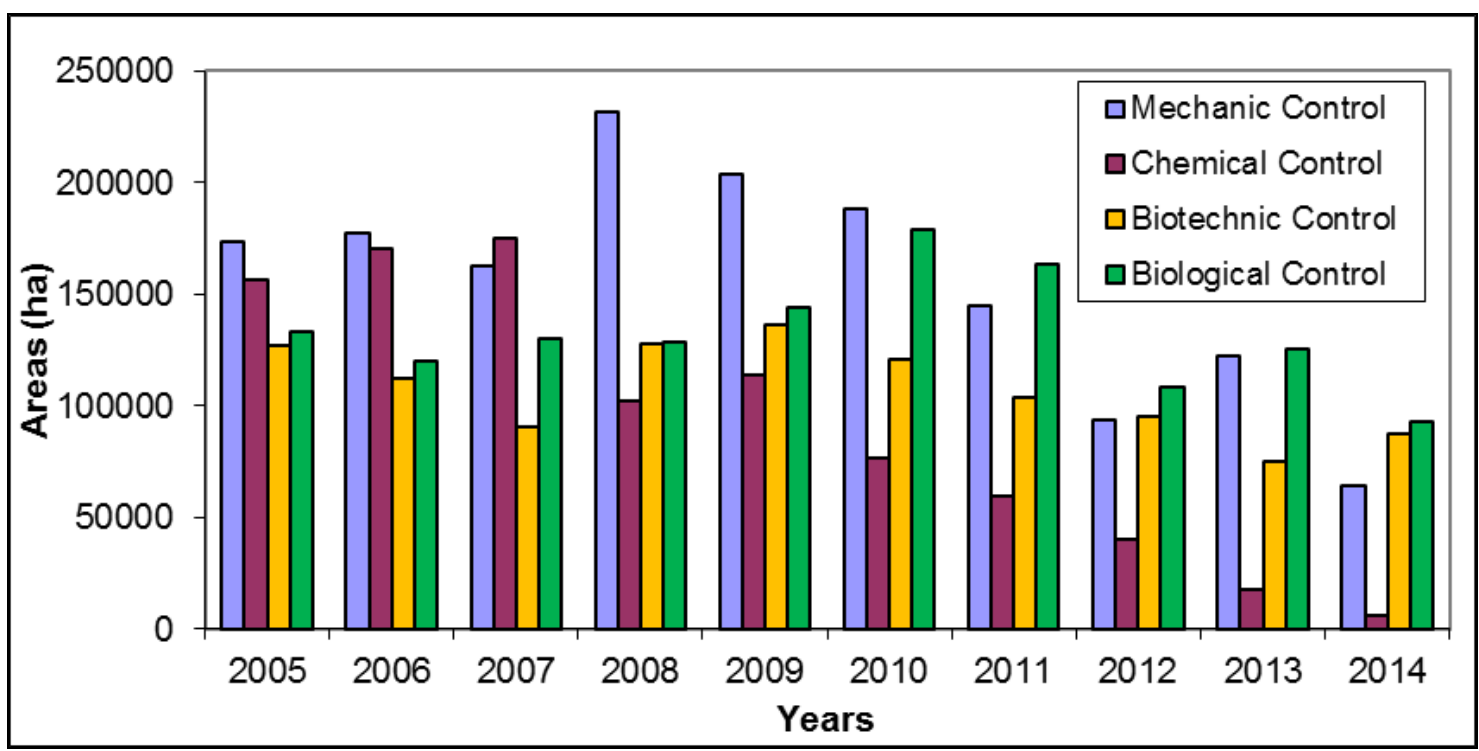

Figure 1. Distribution of control methods by areas in Turkish forests (2005-2014)

Formica rufa (Hymenoptera, Formicidae) is one of the important natural enemies used against the pest insects in Turkish forests. They can feed above and below the soil, and can reach the tops of the highest trees in an area with a radius of 25-100 m 
depending on the individual. It was found that a $F$. rufa colony can kill 100.000 insects within 24 hours (Avc1 et al., 2000). Therefore, four proper nests can control an area of one hectare. For that reason, it is important to use $F$. rufa ants for biological control with a view to protecting the health of forests and ensuring the continuity of the ecological balance (Oğurlu, 2000; Avc1 et al., 2000). F. rufa is naturally distributed intensively in the West Black Sea region located in the northwest of Turkey, most parts of the Black Sea region, some parts of the Marmara, Central Anatolia, and the Inner Aegean region in the west. The forest in Senirkent-Kapıdağ of Isparta province in the southwest of the country constitutes the southern boundary of the distribution area of the species. Their presence in Turkey was identified at an elevation of 950-2000 $\mathrm{m}$ and mainly in Pinus sylvestris forests (Avc1 et al., 2000). The transplantation of $F$. rufa nests started in the 2000s, and increased significantly; successful practices were observed (Fig. 2).

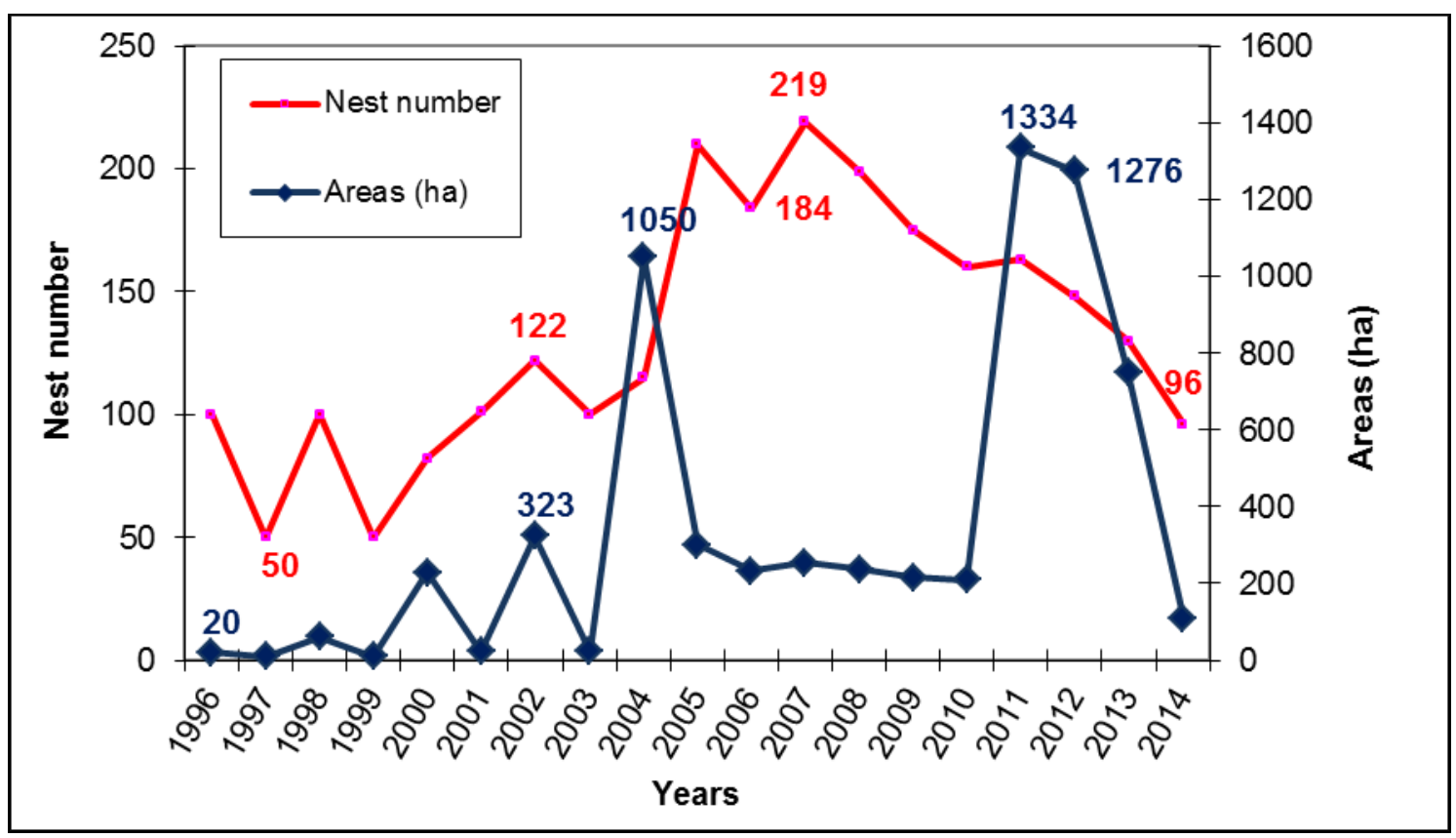

Figure 2. Transplantation of Formica rufa nests (1996-2014)

Calosoma sycophanta (L.) is on one of the most important predatory species for the forestry office in Turkey, produced in biological control laboratories established in different parts of the country and used against pine processionary moths (PPM). Mechanical control of PPM is expensive, while chemical control is known to have an adverse effect on the environment. In contrast, the adults and larvae of $C$. sycophanta that have a lifespan of 3-4 years affect the larvae and pupa of PPM T. wilkinsoni, which is very important for biological control. PPM causes physiological and primary damage on Pinus brutia, P. sylvestris, P. pinea, P. halepensis and P.nigra trees in Turkey. The adults of $C$. sycophanta can kill around 5-10 larvae per day. Considering that the adults can eat 7 PPM a day on average, an adult can kill 280 larvae a year on average, and around 900-1000 larvae on average throughout its life (Kanat et al., 2005; Anonymous, 2006). C. sycophanta is also a predator of Lymantria dispar and Euproctis chrysorrhoea that cause damage to beech, willow, linden and fruit trees. $C$. sycophanta feeds on the 
larvae and pupa of the insects. GDF started rearing this species more intensively especially after 2004, in its biological control laboratories. The method of transplanting the larvae of $C$. sycophanta to the areas where PPM are distributed intensively has been very successful (Fig. 3).

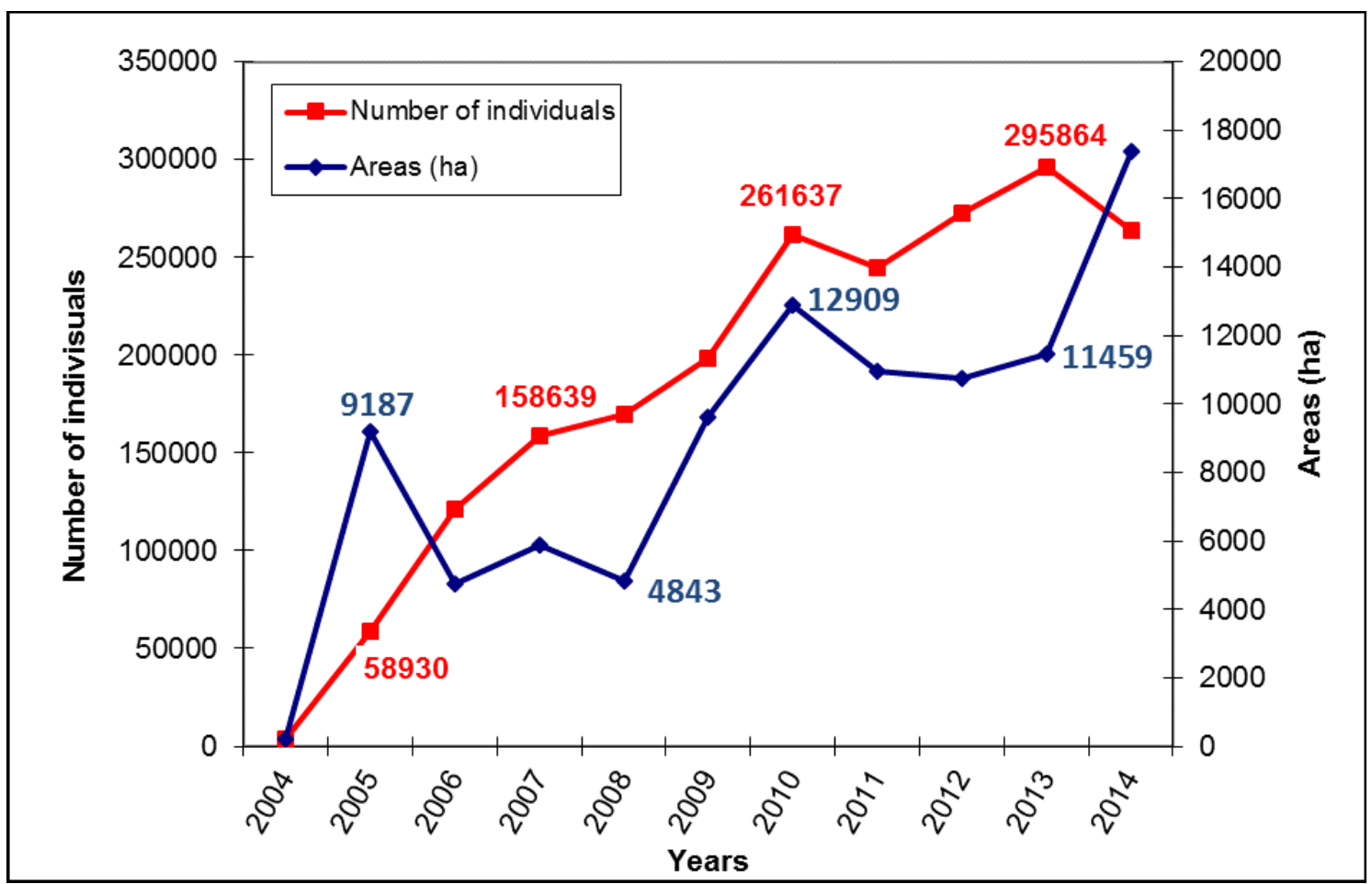

Figure 3. Rearing and application areas of Calosoma sycophanta (2004-2014)

One of the most important predators for bark beetle species in Turkey is Thanasimus formicarius (L.) (Coleoptera, Cleridae). This predator feeds on the adults, caterpillars and pupa of the bark beetles (Ips typographus, Pityokteines curvidens, I. sexdentatus, Orthotomicus erosus and Tomicus minor etc.) that cause damage to all coniferous forests (pine, fir, spruce) (Anonymous, 2006). T. formicarius is an important natural enemy, as it moves fast and thus can capture and kill the bark beetles. T. formicarius produces one generation per year in the East Black Sea region (180-1800 m) located in the northeast of Turkey and the Erzurum Sarıamış location (2000-2400 m) in the east. The flying period of the insect is March-April at $180 \mathrm{~m}$ in the East Black Sea region, and extends from May to September at an elevation of $2000 \mathrm{~m}$ in Erzurum Sarıkamış. Studies show that $T$. formicarius can consume around 10 adult bark beetles per day and around 300 adult bark beetles throughout its lifespan (Akbulut et al., 2005). T. formicarius is a very important predator of I. typographus by feeding on its larvae, pupa and adults. T. formicarius is considered to be an important factor for the stabilization of I. typographus populations. Studies have reported that $81 \%$ of I. typographus in West Germany and 53\% in Switzerland die in the logs where it coexists with T. formicarius. The number of $T$. piniperda also decreased by $92 \%$ in the environment where it coexists with T. formicarius (Yüksel et al., 2001). Akbulut et al. (2005) reported that $T$. formicarius had an effect on all bark beetles, though limited, and it had the most successful proliferation and attack on scotch pine (Pinus sylvestris) and oriental spruce 
(Picea orientalis) forests. T. formicarius is found intensively on the main galleries of $I$. sexdentatus in scotch pine forests, and prefers primarily I. typographus in the oriental spruce forests and then I. sexdentatus. It is determined that it prefers $P$. curvidens (\%16.29) as a main target (Akbulut et al., 2005). T. formicarius is another important species farmed by GDF. This species is currently used in the field against bark beetles to a significant extent (Fig. 4).

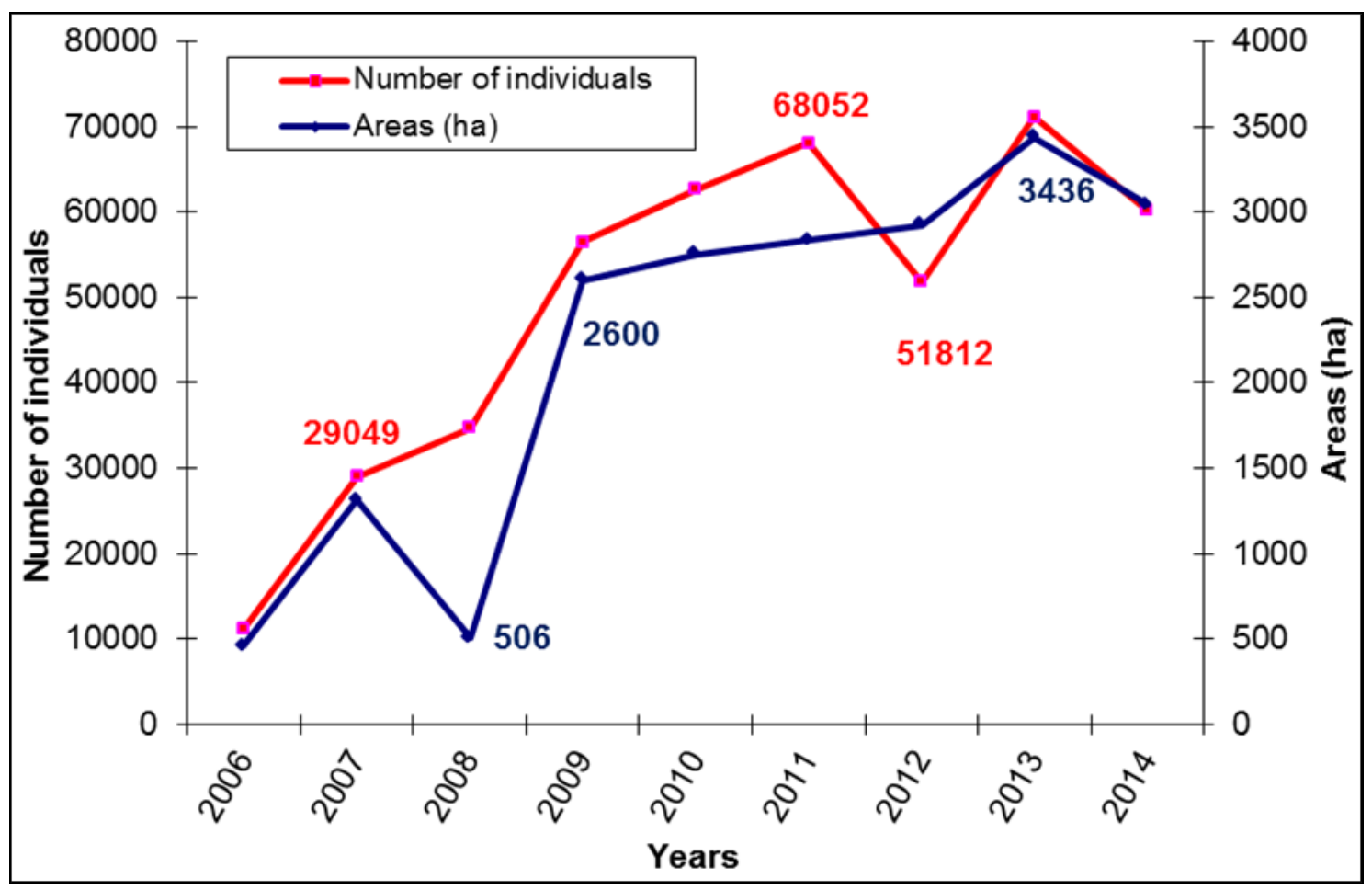

Figure 4. Thanasimus formicarius rearing and application areas (2006-2014)

Rhizophagus grandis Gyll. (Coleoptera, Rhizophagidae) is distributed in the Central and Northern European areas, Baltic countries and Siberia. In Turkey, $R$. grandis is an effective natural enemy of Dendroctonus micans Kug. which causes extensive damage to oriental spruce forests in an area of 75.000 hectares in Artvin and Posof located in the northeast. Bergmüller (1903) first reported that $R$. grandis was an important species in preventing the D. micans epidemics in Europe. Great achievements have been obtained with regard to the control of these insects in Turkey and many European countries. The epidemic of D. micans was mitigated with $R$. grandis by around $80-85 \%$ (Yüksel and Koçyiğit, 2001). Özcan et al. (2005) found that $R$. grandis could control D. micans by $78 \%$.

$R$. grandis is being reared for the first time in Turkey, and has been used successfully for many years against $D$. micans that causes damage to oriental spruce (Picea orientalis) forests. In those treated areas, D. micans is no longer a significant threat and the natural balance has been restored in the spruce forests. As a consequence, the rearing of $R$. grandis has declined since 2009 (Fig. 5). 


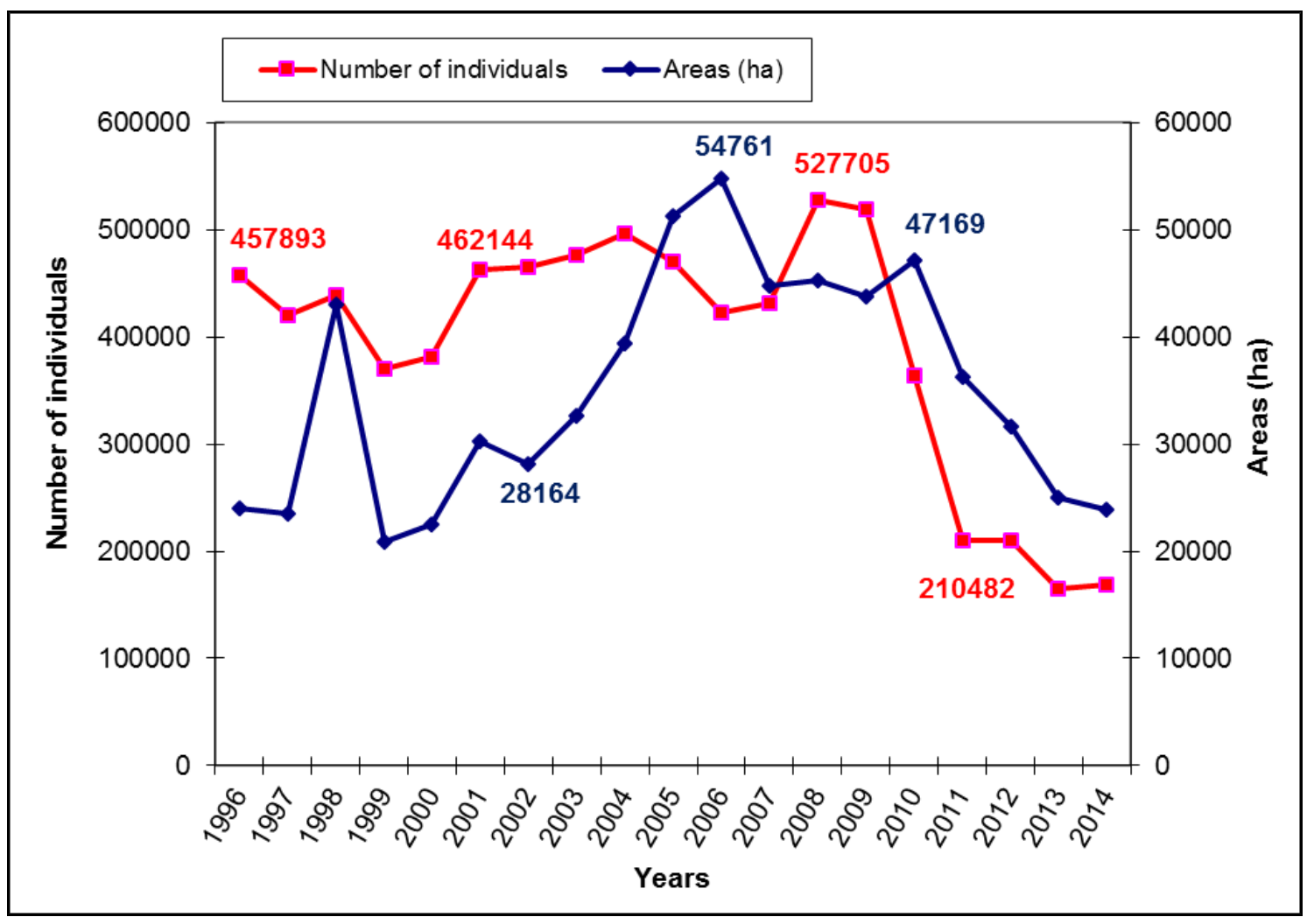

Figure 5. Rhizophagus grandis rearing and application areas (1996-2014)

Rhizophagus depressus (F.) (Coleoptera, Rhizophagidae) is another important predatory of bark beetles in Turkey. This species is distributed in the East Black Sea region at an elevation of 1000-2000 m, in Erzurum Sarıkamıs at an elevation of 2000$2400 \mathrm{~m}$., and in Bolu and Aladag at an elevation of 1000-1700 m. with 2 generations per year. $R$. depressus attacks the nests of I. sexdentatus (58.43\%), I. acuminatus (38.13\%), T.minör (30.49\%) and T. piniperda (29.52\%) in Pinus sylvestris forests. The most important results of $R$. depressus were obtained against the insects that damaged P. sylvestris forests.

Particularly, $R$. depressus has been reported to have high efficacy on the populations of I. sexdentatus in Sarıkamış. The density of this predatory species in the nests of bark beetles in Sarıamıs is at minimum 31.89\% and decreased the harmful population in $T$. piniperda nests by around $41 \%$. The harmful insect species it prefers in the spruce forests are Pityokteines spinidens, O. erosus, and I. typographus (Yüksel et al., 2005). Meydan et al, (2005) reported that the density of $R$. depressus is $39 \%$ in the nests of $T$. minor, $33 \%$ in the nests of T. piniperda, $25 \%$ in the nests of I. acuminatus and $57 \%$ in the nests of $I$. sexdentatus. In the study, it was found to prefer mainly $I$. sexdentatus. While $R$. depressus was reared in the biological control labs of GDF and transplanted to nature in order to prevent the epidemics caused by this bark beetle in Turkey, a more effective species, Thanasimus formicarius, has been reared predominantly in recent years. Therefore, the quantity of $R$. depressus insects reared has declined significantly since 2013 (Fig. 6). 


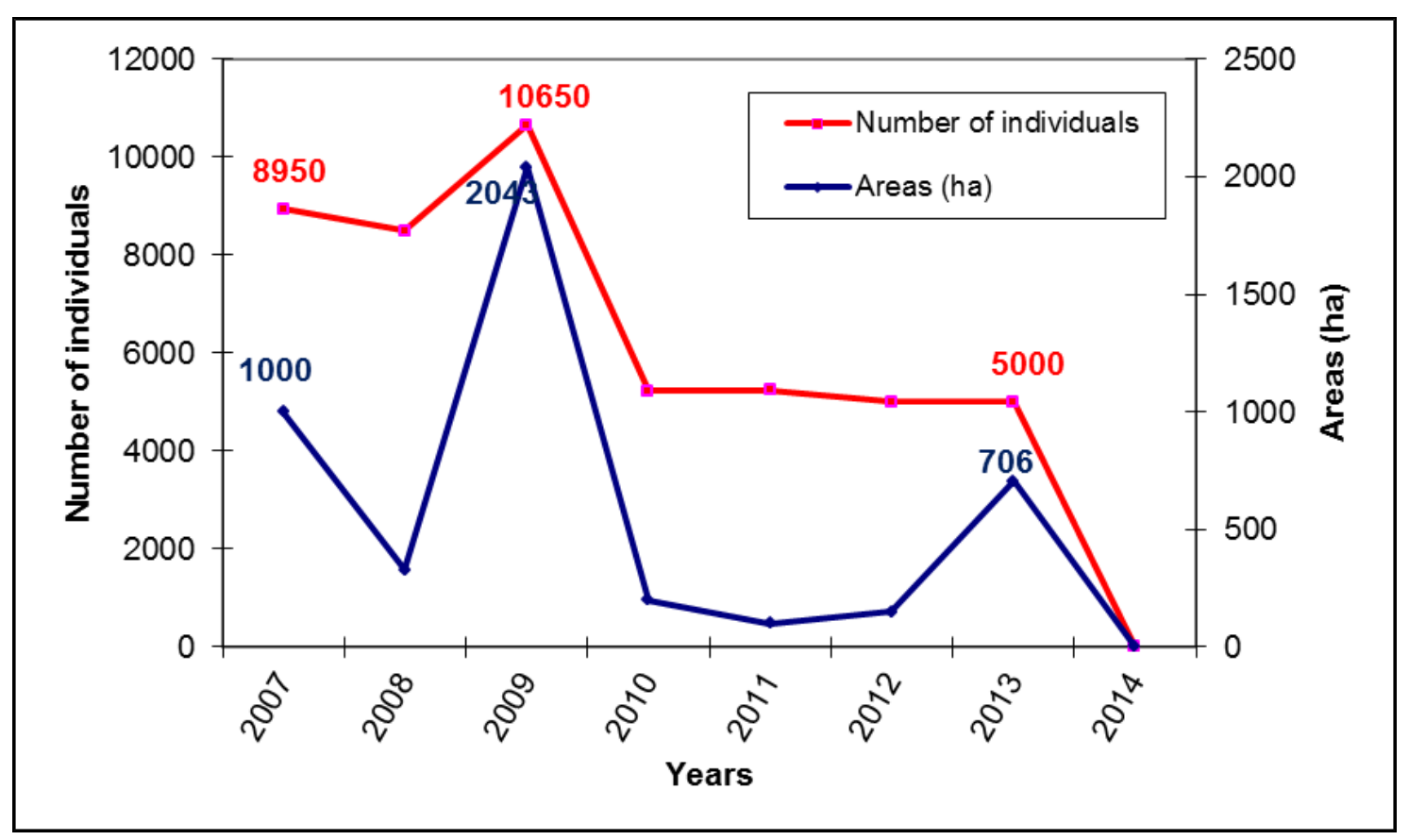

Figure 6. Rhizophagus depressus rearing and application areas (2007-2014)

\section{Economic evaluation of biological and chemical control practices in Turkish forests}

An analysis of the cost of insect control practices performed by the GDF reveals that mechanical control is one of the most expensive (Fig. 7).

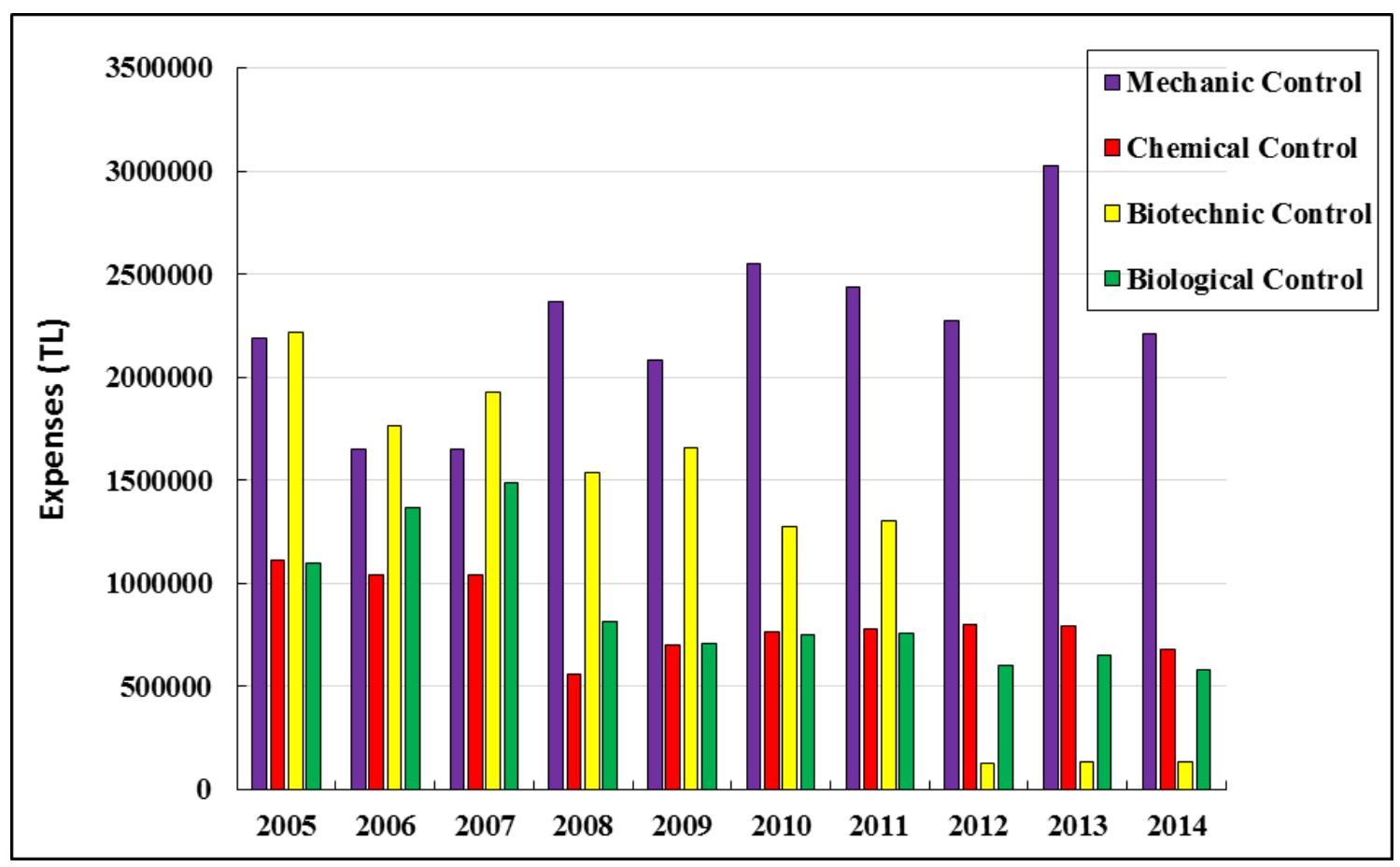

Figure 7. Distribution of the costs of control methods used in Turkish forests (2005-2014) 
This is followed by biotechnic control methods. Fig. 7 shows that the expenditures have declined in recent years thanks to the success of biotechnical control. As for chemical control, the expenditures of GDF fluctuated from 2005 to 2014; overall it had a declining trend. However, as shown by Table 1, although the surface area where the GDF applied chemical control decreased from around 150 thousand ha to 10 thousand ha, it is noteworthy that the expenditures incurred for chemical control did not decline at the same rate. On the other hand, the cost of chemical control declined significantly from 1.113.000 TRY in 2005 to 680.125 TRY in 2014 (Table 1). In other words, although the area where chemical control was applied decreased by 15 times, the money spent for it decreased by only 1.6 times. One of the most important factors leading to that result was that almost all pesticides used for chemical control were imported and the TRY-USD exchange rate was high. Another factor is the need to reapply pesticides in the areas where chemical control failed.

Table 1. Area-cost chart for biological and chemical control practices (2005-2014)

\begin{tabular}{rrrrrrr}
\hline & \multicolumn{3}{c}{ Chemical control } & \multicolumn{3}{c}{ Biological control } \\
\cline { 2 - 7 } Years & Areas (ha) & $\begin{array}{c}\text { Control } \\
\text { costs (TRY) }\end{array}$ & $\begin{array}{c}\text { Adjusted to } \\
\mathbf{2 0 1 5} \text { (TRY)* }\end{array}$ & $\begin{array}{c}\text { Areas } \\
\text { (ha) }\end{array}$ & $\begin{array}{c}\text { Control } \\
\text { costs (TRY) }\end{array}$ & $\begin{array}{c}\text { Adjusted to } \\
\text { 2015 (TRY)* }\end{array}$ \\
\hline 2005 & 156.103 & 1.113 .000 & $2.290 .658,05$ & 133.430 & 1.100 .000 & $2.263 .902,83$ \\
\hline 2006 & 170.379 & 1.038 .499 & $1.915 .544,61$ & 120.153 & 1.366 .706 & $2.520 .932,92$ \\
\hline 2007 & 174.741 & 1.039 .411 & $1.809 .675,40$ & 130.099 & 1.489 .248 & 2.592 .867 .95 \\
\hline 2008 & 102.415 & 557.000 & $897.047,74$ & 128.475 & 814.000 & $1.310 .945,90$ \\
\hline 2009 & 113.550 & 700.195 & $1.064 .523,23$ & 144.109 & 709.527 & $1.078 .710,89$ \\
\hline 2010 & 76.184 & 763.515 & $1.066 .188,16$ & 178.897 & 752.145 & $1.050 .310,86$ \\
\hline 2011 & 59.681 & 780.326 & $961.530,45$ & 163.279 & 760.145 & $936.663,09$ \\
\hline 2012 & 39.741 & 800.269 & $962.497,97$ & 108.641 & 602.589 & $724.744,67$ \\
\hline 2013 & 17.257 & 790.562 & $888.856,37$ & 125.670 & 651.235 & $732.206,18$ \\
\hline 2014 & 5.729 & 680.125 & $718.970,33$ & 120.751 & 576.956 & $609.908,84$ \\
\hline Total & $\mathbf{9 1 5 . 7 8 0}$ & $\mathbf{8 . 2 6 2 . 9 0 2}$ & $\mathbf{1 2 . 5 7 5 . 4 9 2 , 3 1}$ & $\mathbf{1 . 3 5 3 . 5 0 4}$ & $\mathbf{8 . 8 2 2 . 5 5 1}$ & $\mathbf{1 3 . 8 2 1 . 1 9 4 , 1 3}$ \\
\hline
\end{tabular}

*Domestic Producer Price Index (D-PPI) was used for conversion (TUIK, 2017).

Regarding biological control, the expenditures increased from 2005 to 2007, while decreasing in subsequent years (Fig. 7). This is because the GDF increased biological control practices by increasing the rearing of $C$. sycophanta in 2005, $T$. formicarius in 2006 , and $R$. depressus in 2007. The decrease in the cost of biological control starting from 2008 was associated with the effectiveness and success of the control efforts (Table 1). Another point is that the average size of the areas where biological control methods were applied also varied significantly over the years. The average size of these areas decreased over the past years, while the reduction in the costs was more remarkable. This shows that the cost of biological control decreased as the natural balance was restored over the years (Table 1). As Table 1 indicates, the costs in different years were converted to 2015 values for a more robust and accurate interpretation of the total costs of biological and chemical control over a period of years. At that stage, the unit costs were also calculated in order to determine the estimated amount of savings when biological control was preferred over chemical control (Table 2 ). To calculate the estimated amount of savings, it was assumed that biological control 
was preferred to chemical control. Thus, it was presumed that chemical control method was abandoned in the areas where biological control was applied, and the opportunity cost derived was retained by the GDF as savings. Accordingly, the estimated amount of savings in 2015 when the GDF preferred biological control to chemical control was around 1.75 million USD. Furthermore, in addition to this economic profit, the GDF also improved the effectiveness and success of control efforts from 2005 to 2014 on a continuous basis.

Table 2. Unit costs of chemical and biological control and total savings

\begin{tabular}{cccccc}
\hline $\begin{array}{c}\text { Control } \\
\text { Method }\end{array}$ & $\begin{array}{c}\text { Total Control } \\
\text { Cost (TCC) } \\
T R Y\end{array}$ & $\begin{array}{c}\text { Total Area } \\
\text { (TA) } \\
h a\end{array}$ & $\begin{array}{c}\text { Control Unit } \\
\text { Cost }^{1}(\mathbf{C U C}) \\
T R Y / h a\end{array}$ & $\begin{array}{c}\text { Control Unit }_{\text {Cost }^{*}(\mathbf{C U C})} \\
\text { USD/ha }\end{array}$ & $\begin{array}{c}\text { Total Savings }^{2} \\
\text { (TS) }\end{array}$ \\
\hline $\begin{array}{c}\text { Chemical } \\
\text { Control }\end{array}$ & $12.575 .492,31$ & 915.780 & 13,73 & 5,05 & \\
\hline $\begin{array}{c}\text { Biological } \\
\text { Control }\end{array}$ & $13.821 .194,13$ & 1.353 .504 & 10,21 & 3,75 & $1.751 .840,23$ \\
\hline
\end{tabular}

${ }^{1} C U C=T C C / T A, \quad{ }^{2} T S=T B C A *(C C U C-B C U C)$

TBCA: Total Biological Control Area, CCUC: Chemical Control Unit Cost, BCUC: Biological Control Unit Cost

*Central Bank of Turkey average TRY-USD exchange rate of $2015(1$ USD $=2.72$ TRY $)$

The economic analyses on biological and chemical control show that the cost of biological control is 3.75 USD per ha, compared to about 5.05 USD per ha for chemical control. These findings indicate that chemical control is 1.4 times more expensive than biological control in Turkey. An evaluation reveals that one of the most important factors affecting this difference is that the pesticides used for chemical control are imported and expensive. Moreover, harmful insects became resistant to the insecticides, requiring supply of new chemical compounds. This factor increases the cost of every new insecticide. For chemical control to succeed, pesticides have to be applied to the area until results are seen, which is another reason for the increased cost. Furthermore, special protective clothing, equipment and tools are needed to apply the pesticides in the field during chemical control. Annual periodical maintenance also increases the cost of chemical control. The cost of biological control is high initially, but decreases as the balance of the ecosystem is restored over time. The predators left in the area reproduce on their own and reduce the pest insect population below the economic loss threshold. Typically, it is not necessary to transplant the predators to the site every year. In other words, repetition is either not needed or very limited, which decreases the overall cost significantly. Another point related to cost is that the GDF employs its own laboratories and technical staff for the rearing of predators. Contrary to chemical control, they are not imported; therefore, the cost of rearing predators is low. Moreover, there is no need to use special clothing and equipment during the field application of biological control, which also decreases the cost.

\section{Conclusions}

In this study, the current status of biological control practices addressing pest insects in Turkish forests was analysed and compared with chemical control methods from an economic perspective. The first biological control was applied in Turkish forests in 1967, when Formica rufa was transplanted. However, the efforts regarding biological 
control were not that extensive until the 2000s. Turkish forestry organizations needed to take action because: the pesticides used with chemical control were harmful for the forests and human health, the chemical compounds used for the preparation of these pesticides were expensive, and the insects developed resistance against the pesticides. As a result, biological control efforts were increased especially after 2000 in Turkish forests, while the chemical control practices were eventually abandoned. This indicates the importance that the Turkish forestry organization attaches to the biological control method especially in recent years.

In particular, C. sycophanta since 2004, T. formicarius since 2006 and $R$. depressus since 2007 have been predominantly reared and extensively used during biological control operations. The quantity of these species and the areas where they are used have increased over the years and significant achievements were obtained. It is important from the ecological perspective that natural balance is restored gradually in these areas where biological control is applied. However, the economic aspects of insect control efforts are as important as the ecological aspects. From this perspective, an important finding of this study was that significant economic savings were obtained in addition to the ecological benefits as the chemical control was abandoned. The successful results including cost savings obtained by biological control practices add to point to the fact that the ecological balance in Turkish forests is gradually being restored.

The economic analyses revealed that the cost of biological control was around 3.75 USD per ha as compared to around 5.05 USD per ha for chemical control. Thus, when the ratio of the unit costs are calculated, it was found that the chemical control method was around 1.4 times more expensive than the biological control method. It is estimated that the economic savings will further increase as the areas where biological control is applied are extended, and the areas where chemical control is applied are reduced. Indeed, as the ecosystem gains back its natural balance in time through biological control, the cost of biological control per unit area will decrease; therefore, it is estimated that the economic savings will further increase. Thus, biological control is the most economic method for Turkish forests. The analyses revealed that the economic saving derived by abandoning chemical control methods is estimated at around 1.75 million USD in 2004-2014.

In conclusion, the primary benefit of biological control is that it restores ecological balance and thus ensures continuity of the ecosystem services. Its secondary benefit is the cost savings it brings. Therefore, the use of biological control methods to address pest insects in Turkey's forest ecosystems contributes remarkably to ecological and economic sustainability.

\section{REFERENCES}

[1] Akbulut, S., Yüksel, B., Serin, M., Erdem, M.,Ünal, S., Baysal, İ. (2005): Relationships with main hosts of Thanasimus formicarius (L.) (Coleoptera: Cleridae) and its role in biological control in oriental spruce, the Scoth pine and fir forests. - Karadeniz Technical University Faculty of Forestry, Spruce Symposium, Trabzon, Turkey, 20-22 October 2005, 1:316-327.

[2] Akyol, A., Tolunay, A. (2014): Modelling of sustainable forest management criteria and indicators for Turkey. - Turkish Journal of Forestry 15: 21-32.

[3] Anonymous (2006): Predator beetle production. - The Journal of Forestry General Directorate News, April-May-June, 12-13. 
[4] Atmış, E., Özden, S., Lise, W. (2007): Urbanization pressures on the natural forests in Turkey: An overview. - Urban Forestry \& Urban Greening 6(2):83-92.

[5] Avc1, M., Morkoyunlu, M., Y1lmaz, A. (2000): Formica rufa L. and transplantation applications in Isparta province. - Ministry of Forestry, Technical Bulletin 2: 22-26.

[6] Bergmüller, H. (1903): Dendroctonus micans und Rhizopgagus grandis, Centralbl. f.d. ges. - Forstwesen 29: 252.

[7] Bokonon-Ganta, A.H., Groote, H., Neuenschwander, P. (2002): Socio-economic impact of biological control of mango mealybug in Benin. - Agriculture, Ecosystems and Environment 93: 367-378.

[8] Born, W., Rauschmayer, F., Brauer, I. (2005): Economic evaluation of biological invasions-a survey. - Ecological Economics 55: 321- 336.

[9] Brower, J.H. (1991): Potential host range and performance of a reportedly monophagous parasitoid, Pteromalus cerealellae (Hymenoptera: Pteromalidae). - Entomol. News 102: 231-235.

[10] Deniz T., Ok, K. (2015): Valuation analysis in erosion control activities. - Istanbul University, Journal of Forestry Faculty 66(1): 138-158.

[11] Dijken, M.J., Kole, M., van Lenteren, J.C., Brand, A.M. (1986): Host-preference studies with Trichogramma evanescens Westwood (Hym., Trichogrammatidae) for Mamestra brassicae, Pieris brassicae and Pieris rapae. - J. Appl. Entomol. 101: 64-85.

[12] Fowler, S.V., Gourlay, A.H., Hill, R. (2016): Biological control of ragwort in the New Zealand dairy sector: an ex-post economic analysis. - New Zealand Journal of Agricultural Research 205-215.

[13] GDF (2015). Statistical data on controlling of forest pests in 2014. - General Directorate of Forestry. Ankara, 126 p.

[14] Greathead, D.J. (1976): A Review of Biological Control in Western and Southern Europe. - Technical Communication No. 7. CIBC, CAB, Farnham Royal, Slough.

[15] Güngör, E., Daşdemir, İ. (2014): Economic impacts of Fir Engraver Beetle in the forests of Bartın region, Turkey. - 2nd Symposium of Turkey Forest Entomology and Pathology, Symposium Proceedings, Antalya, Turkey, 7-9 April 2014, pp.187-196.

[16] Kanat, M., Toprak, Ö., Akbulut, S. (2005): Determination of some biological characteristics of Calosoma sycophanta L. (Coleoptera: Carabidae). - Turk. J. Zool. 29: 67-71.

[17] Mc Fadyent, R. (2008): Return on investment: determining the economic impact of biological control programmes. - Keynote speaker, Cooperative Research Centre for Australian Weed Management, 67-74.

[18] Meydan, M., Göktürk, T., Aksu, Y. (2005): Investigations on producing of Rhizophagus depressus (Fabr.) (Coleoptera: Rhizophagidae) in laboratory conditions and using possibilities in biocontrol applications. - Karadeniz Technical University Faculty of Forestry, Spruce Symposium, Proceeding Book, Trabzon, Turkey, 1:214-221.

[19] Oğurlu, İ. (2000): Biological Control. - Süleyman Demirel University Publications, No:8, Isparta.

[20] Orr, D. (2009): Biological Control and Integrated Pest Management. - In: Peshin, R., Dhawa, A. K. (eds) Integrated pest management: innovation-development process. Springer: Jammu.

[21] Özcan, G.E., Eroğlu, M., Alkan-Akınc1, H. (2005): Total activity and production problems in biological control of Dendroctonus micans (Kugelann) (Coleoptera: Scolytidae) by Rhizophagus grandis Gyll. (Coleoptera: Rhizophagidae). - Karadeniz Technical University Faculty of Forestry, Spruce Symposium, Turkey, 20-22 October 2005, 1:174-183.

[22] Pak, M., Türker, M.F., Öztürk, A. (2010): Total economic value of forest resources in Turkey. - African Journal of Agricultural Research 5: 1908-1916. 
[23] Tolunay, A., Türkoğlu, T. (2014): Perspectives and attitudes of forest products industry companies on the chain of custody certification: A case study from Turkey. Sustainability 6(2): 857-871.

[24] TUIK (2017). Turkish Statistical Institute. www.tuik.com.tr (accessed on 20 Jaunuary 2017).

[25] Uygun, N., Ulusoy, M.R., Satar, S. (2010): Biological control. - Turkish Journal of Biological Control 1: 1-14.

[26] Van Lenteren, J.C., Babendreier, D., Bigler, F., Burgio, G., Hokkanen, H.M.T., Kuske, S., Loomans, A.J.M., Menzler-Hokkanen, I., Van Rijn, P.C.J., Thomas, M.B., Tommasini, M.G., Zeng, Q.Q. (2003): Environmental risk assessment of exotic natural enemies used in inundative biological control. - Biocontrol 48(3): 3-38.

[27] Yüksel, B., Akbulut, S., Serin, M., Erdem, M., Baysal, İ. (2005): Relationships with main hosts of Rhizophagus depressus (Fabr.) (Coleoptera: Rhizophagidae) and its role in biological control in oriental spruce, the Scoth pine and fir forests. - Karadeniz Technical University Faculty of Forestry, Spruce Symposium, Turkey, 1:195-205.

[28] Yüksel, B., Eroğlu, M., Bilgili, E. (2001): Relationships with main hosts of Thanasimus formicarius (L.) (Coleoptera: Cleridae) and its role in biological control in the Scoth pine and oriental spruce forests. - Forest Engineering 11: 8-14.

[29] Yüksel, B., Koçyiğit, M. (2001): Alternative mass producing methods for the predator of great spruce bark beetle Rhizophagus grandis (Gyll.) (Coleoptera: Rhizophagidae) Rapid Establishment of Biotic Equilibrium 6: 11-14. 